\title{
Practice Led Research: Creative Activity, Academic Debate, and Intellectual Rigour
}

\author{
Josie Arnold \\ Professor of Writing, Swinburne University of Technology \\ School of Social Sciences, Higher Education, Lilydale \\ Locked Bag 218 Lilydale, Victoria 3140, Australia \\ Tel: 61-304-1617-4808Ｅ-mail: jarnold@swin.edu.au
}

Received: February 2, 2012

Accepted: February 3, 2012 Online Published: April 18, 2012

doi:10.5539/hes.v2n2p9

URL: http://dx.doi.org/10.5539/hes.v2n2p9

\begin{abstract}
By focussing on $\mathrm{PhD}$ supervision as well as creativity, this paper explores how the artefact and exegesis PhD offers an opportunity to bring creative activity together with academic debate and intellectual rigour. In this context, the latter does not justify the former nor interpret it in an academic and theoretical way. Rather, acting together, the artefact and exegesis bridge the Cartesian binary, offer new models of knowledge to the academy, and enrich the artistic practices of the practitioners themselves. The creative practitioner thus brings to the academy new dimensions of what knowledge itself consists of and how this contributes to learning. Because this disputes the regular academic templates, it challenges the academy itself. The methodology I employ in this paper is one of narrativity that I call the 'subjective academic narrative', it practices the theory of academic knowledge as personal and draws together the Cartesian binary of the personal and the intellectual.
\end{abstract}

Keywords: Creativity, Narrativity, PHD supervsion

\section{Introduction}

Today, whilst paradoxically deleting many arts-based courses from their curricula, many Australian universities are becoming more open to creative practice-led research as knowledge.

The philosopher Peter Singer (2009:15) states that:

'....an educated citizen in a free society should have a grounding in philosophy, literature, the sciences, maths, foreign languages, politics and fine arts...This kind of education does not train you in a profession, but it gives you an intellectual foundation to use throughout your life...'

This kind of education is also basic to creativity throughout our social fabric; and creativity is also an important contributor to the economic as well as social well-being of our culture. Creative Industries contribute significantly to Australia's economic as well as social and cultural well-being.

The Department of State and Regional development report 'NSW Creative Industry: Economic Fundamentals' 2008 defines creative industries rather traditionally as:

'advertising; architecture; design; visual arts; music; performing arts; publishing; film; television; radio electronic games' by their own scope rather than including 'downstream stages...such as manufacturing, wholesale, distribution, retailing and second hand sales.’(2008:7)

So the role of creative industries in the economic welfare of Australia is a large and growing one. The report states that:

'The creative industry is a significant component of NSW's economy, employing over 5 per cent of the workforce (of 150,000) Further, over the 10 years to 2006, employment in the creative industry increased by 28 per cent, against 13.5 per cent for all industries.’ (2008:8)

It adds a cautionary note: 'creative industry employment growth across Australia was marginally higher than for NSW" (2008:10)

Creative industries employ large sections of the Australian community quite directly. The above report quotes the OECD estimates of cultural/creative contributions in Australia as 3.1\% of the GDP, comparable with Canada at 3.5\%; France at 2.8\%; and the U.S .A. at 3.3\% but outflanked by the UK at 5.8\%. (pp8) Such industries also engage 
informally many creative artists as part of developing their own subjective selves to transform society. Strangely, until quite recently, they have been largely ignored by Universities dominated by traditional models of knowledge and now turned into business models themselves.

There are strong economic as well as cultural reasons, then, that today, whilst paradoxically deleting many arts-based courses from their curricula, many Australian universities are becoming open to creative practice-led research as knowledge. (Oakley: 2004)

The opportunities presented by the creativity and research nexus are potentially transformative as they provide us with the ability to look at the world in new ways, to look through different prisms and lenses and through other people's eyes so as to develop new aesthetics.

Bringing the creative industries as areas of artistic exploration into traditional research meets challenges such as:

- $\quad$ Becoming reductive and explanatory

- Analysing the non-traditional from a traditional position

- Setting industry and academe against one another

- $\quad$ Setting up academic priorities for creative works

Practitioner-academics have always existed, making strong research contributions through their creativity in such areas as writing, history, design and architecture. Practice-Led Research expresses a relatively new tension between such players as:

- The art world

- Industry

- $\quad$ Arts practitioners

- Intellectual paradigms of knowledge theory and practice

Today there is a proliferation of different models for bringing together practice and research in the academy. PLR has been a term that encompasses them rather than being exclusive. It encompasses such desciptors as 'practitioner based research' and 'studio based research'. The goal really is inclusion rather than exclusion of the ways in which practice and research can co-exist as fruitful ways of knowing within the academic discourse about methodology and theory, and the old qualitative/quantitative debate.

In writing, there has been an explosion of such courses and today there are 26 Australian Universities that offer a $\mathrm{PhD}$ in writing by artefact and exegesis. This means that there is an increasing challenge to understand and illustrate non-traditional methodologies within a non-traditional framework.

\section{Methodology}

There has been a considerable growth of understanding the postmodernist position that qualitative methodologies based upon singular experiences contribute in a scholarly way to knowledge itself. This paper is based upon the premise that one academic's experience at one institution is of value to the identified academic debate. Other scholars have indicated various insights into this. Sarah Wall states that: 'autoethnography is an emerging qualitative research method that allows the author to write in a highly personalised style, drawing on his or her experience to extend understanding...the intent of autoethnography is to acknowledge the inextricable link between the personal and the cultural and to make room for non-traditional forms of enquiry and expression.' 2006:146) Writing about my own experiences and the insights that they offer, then, becomes a qualitative methodology that reside readily within the autoethnographic frame. Nicholas Holt sees this as ' .... genre of writing and research that connects the personal to the cultural, placing the elf within a social context.' (2003:18). For him, an academic article is a 'writing story' that challenges traditional academic claims of verification and disinterestedness.

Such autoethnographic methodology sits easily beside Gregory Ulmer's idea of a 'mystory', Following this mystorical approach, I bring to this paper my personal observations and reactions as well as my academic reading and thinking. Ulmer (1985) identifies a 'mystorical' approach to thinking and research. A 'mystory' puts under erasure all claims to fact/authenticity in writing. It shows all writing to be both personal and mysterious (my story and mystery) whatever its claims to authenticity and depersonalisation. It reveals the academic text to be sewn together as a compilation of the scholarly, the anecdotal or popular, and the autobiographical. It questions the dominant analytico-referential model of knowledge.

Jane Gallop proposes that 'anecdotal theory' is a feminist activity that enables non-patriarchal ways of thinking and doing academic work. It aims to 'tie theorizing to lived experience... anecdotal theory must be...the juncture where 
theory finds itself compelled -against its will, against its projects- to think where it has been forced to think.' (Gallop 2002:15)

Carolyn Ellis speaks of 'the first person voice, the vulnerability of the observer, the performative voice...that blurs the line between researcher and participant, writer and reader' (Bochner \& Ellis 2003:509). Thinking such as this has led me to my own conceptual methodological attitude has formed within this academic debate about knowledge, the idea of 'the subjective academic narrative' (Arnold 2010) as underpinning my academic writing. An understanding of the personal nature of all 'stories', whatever genre or structure has impacted upon all forms of knowledge.

\section{How do I see the needs of creative practitioner higher degree students at Swinburne University of Technology?}

The artefact and exegesis model of the $\mathrm{PhD}$ in writing at Swinburne University of Technology offers an opportunity to bring the creative activity together with the academic debate and rigour. In this context, the latter does not justify the former nor interpret it in an academic and theoretical way. Rather, acting together, the artefact and exegesis bridge the Cartesian binary, offer new models of knowledge to the academy, and enrich the artistic practices of the practitioners themselves.

Illuminating and articulating practice as knowledge is a challenge in an academic environment that has not always seen practice as knowledge and often still struggles to do so. In this sense we must reject the idea that the exegesis is legitimising creativity, or indeed that bringing creativity into the academy so directly is in itself a legitimisation rather than an acknowledgement of creativity as knowledge. (Maarit 2007)

The creative practitioner brings to the academy new dimensions of what knowledge itself consists of, and how this contributes to learning. Because this disputes the regular academic templates, it challenges the academy itself. This means that practice-led research students are engaged in defining their model in ways that traditional research students are not. (Harper 2008)

Richard James and Gabrielle Baldwin (1999) affirm the desirability of a dynamic realization of the multiple possibilities of research:

'Research differs across the disciplines. What constitutes a contribution to knowledge and how this contribution is presented, differ similarly - creative novels, performances, and CD-ROMs, for example, are now establishing themselves in certain disciplines as alternatives or complements to the written thesis. Regardless of these differences in research cultures, all research involves critical enquiry, the strenuous intellectual activity of collecting, sifting and analyzing information and presenting new knowledge’ (James \& Baldwin 1999.p.3).

Recognising the diversity of research outcomes, the examinable components of the PhD in Writing at Swinburne University of Technology consist of either:

- A genre work that is accompanied by an exegesis. or

- A traditional dissertation on textuality and discourse and/or elements of the writing process usually referred to as the thesis.

The first non-traditional option is the one under discussion here. I call this the exuberant $\mathrm{PhD}$ because of its dynamism in producing a practice-artefact and a scholarly-exegesis.

The artefact-as-knowledge offers Swinburne writing $\mathrm{PhD}$ students the capacity to produce a substantial piece of work (approximately an 80,000 word text or the equivalent in its genre or form) that is suitable for publication: meaning suitable for presentation to publishers. The artefact may be in one of the following broad genre categories or may include a number of them:

- $\quad$ creative writing ( for example, a novel, a screenplay, a multimedia production, a book of poetry, a stage play)

- $\quad$ research writing (for example, a scholarly book; a series of scholarly papers)

- $\quad$ curriculum writing (for example, a major curriculum plan, a textbook, a series of subject guides)

- business writing (for example, a company report; occupational health and safety; advertising manuals, strategies and guidelines).

This is accompanied by an exegesis of approximately 20,000-30,000 words. The style and presentation of this exegesis, and especially its intent and relationship both to the artefact and to knowledge provides us with a dynamic debate. The 2 must 'speak to' one another and form a whole together. This model has attracted candidates from the writing industry, from our Master of Arts (Writing) as well as from other disciplines such as tourism and psychology. 


\section{What key areas are central to good supervision in creative practice?}

Supervising Practice Led Research (PLR) both enables me to develop a broader view of knowledge than conventional academic gatekeeping, and involves me in a significant teaching and learning experience. For me, $\mathrm{PhD}$ supervision in this model has both called upon and developed deep pedagogical knowledge and insights. I agree that:

'Supervising doctoral candidates is among the most important work that university staff can undertake. It is quite rightly regarded as the most significant and intensive teaching and mentoring experience accorded an academic.'(Denholm \& Evans 2007:1).

There are new challenges for me in developing an understanding of the pedagogical practices involved in supervising $\mathrm{PhD}$ candidates in PLR that, in the Swinburne University of Technology model for the Writing Discipline, culminates in a submission of a preface, artefact and exegesis. For me, these include me as a supervisor in:

- $\quad$ responsibilities in developing pedagogical insights

- $\quad$ personal interactions and support

- $\quad$ stepping back as well as stepping forward

- $\quad$ signposting for cohesive productions

- $\quad$ editing as an informed critic/critical friend

- $\quad$ knowledge of genre inscription

- $\quad$ insights into textuality and discourse questions

- $\quad$ broad knowledge of critical theories

- $\quad$ sound academic and editing abilities.

My interest lies in how to produce a directive and supportive yet non-didactic supervision that enables both the candidate and the supervisor. This means that I am focussed upon the pedagogical aspects of supervising candidature in PLR in the PhD writing program. In particular, it leads me to reflect upon what I've learnt about how supervising $\mathrm{PhD}$ candidates in writing at Swinburne is intrinsically a pedagogical act as well as a research activity. It has led me to an understanding that, just as research is an essential element of teaching, so teaching is an essential element of research supervision. This may exhibit itself explicitly, or be an implicit pedagogy.

This paper recognises that each supervisory interaction is highly individual, but places each within a broader educational philosophy and practice on the part of the supervisor. In doing so, it also proposes that each candidate enters what they believe to be a pastoral learning and teaching situation within a research context underpinning a personal research journey leading to significant new contributions to knowledge.

The PhD journey is one of what Johnson et al describe as a 'fantasy' in which the candidate is under supervision yet somehow independent and autonomous. They call this an 'invisible pedagogy' of 'liberty under surveillance'. (2000:143) Whether 'invisible' or not, the importance of a pedagogical framework supporting both supervisor and candidate as well as ensuring that University standards and those of the Academy are met, cannot be underestimated. The Swinburne Writing Discipline artefact and exegesis model of the writing PhD facilitates the independence of the scholar/producer through Practice Led Research. (Arnold. 2005; 2007)

Deidre Barron and Margaret Zeegers describe '...pedagogy as a crucial element in postgraduate research undertakings, implying active involvement of both student and supervisor in a process of teaching and learning.' (2002:1) They agree with Lee Johnson et al that the traditional supervisor/candidate model of interaction is masculinist. While it is not within the scope of this paper to pursue that line of thinking, I acknowledge its importance. Such masculinist and patriarchal knowledge models are inflexible and contribute to the Cartesian binary that I believe PLR bridges.

Higher education is undergoing a fundamental shift in the supervision of $\mathrm{PhD}$ students and in the admission of PLR as credentialled knowledge. (Bourke and Neilson (eds) 1996. Denholm and Evans (eds) 2007) Rather than supervision being conducted within traditional frameworks of knowledge, this involves me as supervisor in understanding my role as a teacher in a learning situation as well as one whose whole aim is to finally step right away and allow the candidate to become the expert. Being called a 'supervisor' rather than a 'teacher' is a confusing element that seems to deny the pedagogical foundation of $\mathrm{PhD}$ candidature. In their discussion of the importance of this pedagogical foundation, Johnson et al identify the patriarchal elements implicit in the traditional higher education terms of 'supervisor' and 'candidate': 
، “Supervision” carries powerful overtones of 'overseeing' (of 'looking over' and 'looking after') production and development with regard to academic knowledge and identity...the student (the 'candidate') and the dissertation are to be constructed under the authorized and authorizing gaze of an already-established researcher, standing in, in some sense, for the field of study in question and for the Academy more generally' (Johnson \& Green: 142)

Yet supervision is both more and less than this as it is an intense relationship between the researcher and the supervsiors with knowledge, University guidelines, the research section of the University and examiners.

\section{Supervision}

Undertaking any $\mathrm{PhD}$ supervision calls for rigour. Challenging reductive empiricist notions of research through Practice Led Research intensifies this process for both candidates and supervisors. Also, in the artefact/exegesis PhD, there are 2 distinct yet interactive elements to be considered.

Supervision in my experience has a particular trajectory that calls for certain interactions over the course of the project. This consists of an upward curve over the first year or so that indicates the importance of the supervisor as 'hands on' helper. This results in the first rough draft of the artefact and the establishment of the guidelines for the exegesis drawing on the working diary that has been developed over this period of time.

The trajectory then flattens out as the candidate takes more and more responsibility for researching the academic dimensions of the exegesis and their relationship to their practice. This is a troubling and exciting time for both supervisor and candidate. The supervisor is more hands-off whilst at the same time directing the student to move into the current academic debates that their practice and their reflections upon that practice open up for them and to which they contribute.

This is a time in which the exegesis prevails. The exegesis reveals its potential for/to the practitioner. The exegesis, then, acts as:

- $\quad$ not 'the enemy' to creativity

- full of potential for another creativity and area of invention

- $\quad$ an essential element of the transformational process of the PHD

- a privileged space for the candidate/practitioner to work in

- clarifying the project to show what is being done and why this is a new and significant contribution to knowledge

- $\quad$ indicating clearly the methodology of the artefact as well as the methodology of the thinking this practice has developed about itself

- $\quad$ a space in which uncertainty and lack of direction show themselves as essential elements in finding definition of the candidate's practitioners through the literature and current debate

- $\quad$ a place for experimentation with thought and interaction with other academics and practitioners

- $\quad$ showing wonder, creativity and surprise as it reviews and revalues the work undertaken in the artefact and in entering the academic debates that are relevant

In this central and latter part of the candidacy, the candidate begins to more and more own the project and to see the supervisor as a 'critical friend' rather than co-developer of the project. The candidate becomes increasingly self-reliant as the supervisor draws away from an empathic and supportive role through that of a critical friend into the final phase of a quasi-examiner.

In this latter phase, then, we have a first rough draft of both the artefact and the exegesis. These are now ready for the hard and on-going work that is the hallmark of any good research report, journal article, book, and traditional or artefact and exegesis PHD.

Much of this is mundane and routine hard work by the candidate. For both supervisor and candidate it involves:

- managing expectations about the reason for undertaking the candidacy and the graduate outcomes

- $\quad$ managing the project for feasibility; time-frame; ethics clearance; usefulness and relevance of research; positioning the work in the field

- training the candidate in skills for practice and industry; developing transferable skills; being flexible and professional; working within multiple cultural paradigms

- $\quad$ understanding theory and its practical implications

Now we might be considering such areas as: 
- Doing-reflecting-researching (what about the artefact and its success within its genre; references? What about what other academics are saying?)

- How is our foundational material in both the artefact and exegesis revealing itself to be appropriate for its 'ideal' or 'target' audience?

- $\quad$ Finding the tacit and explicit in our artefact and explicating it to others

- Showing the intricacies and subtle nuances of each element in themselves and as they relate to one another

- Making art explicit from the aesthetic and felt for the community of art and relating it through the research traditions available to the community of knowledge

Addressing the examiners is the final high-point of supervision and the period in which we as supervisors become quasi-examiners.

Insert Figure 1 about here.

\section{The Candidate's Trajectory}

1) proposal and selection of supervisors: This is not always managed as well as it might be. Potential candidates may need more help with this than usually given as they often come from the writing industry and/or from a non-traditional background of dealing with University applications.

2) working journal commences and proceeds. This is the connective link between the artefact and the exegesis that is really like data collection in the traditional sense, I suppose.

3) reads in chosen genre. The artefact must sit well within its own genre. I ask my candidates to go into a bookshop and stand next to where they think their book will be displayed: they then get a taste of what's there, how it's presented, how it's marketed etc. Reading in this genre also gives them references for their artefact. Some candidates may decide not to do this if they fear subconsciously copying the published writer, but I think if it occurs before they begin to write it situates them into the professional standards and demands of writing for publication.

4) begins to write rough first draft of artefact. Before this begins, I ask candidates to write a publishing proposal so that they can understand the industry demands of their writing. This also clarifies in their own minds the ideal readers for their artefact.

5) reads other writers on writing in this genre. A major new and significant contribution occurs in the exegesis when the writer analyses her or his work in the artefact. Part of this explanatory matter is to see what other writers in this genre may have to say to illuminate the process of writing.

6) identifies relevant areas of academic interest from journal. Artefact writing and reading contributes a genre and industry knowledge of the work of PLR. The major new and significant contribution to knowledge that comes from practice led research is that it can be situated within current academic insights and debates into issues that have arisen from the writing of the artefact, and from the reading of genre, other writers' insights and academic materials. I call this the licorice allsort approach: each layer may be tasty, but together they are greater than each part.

7) plan of exegesis to rough first draft. The writing journal can be mined for headings as issues arise regularly throughout. These issues can become heads and there are also sub-heads that have revealed themselves through the writing journal. In this way the skeleton plan of the exegesis may start to form itself and can be informed/fleshed out by further insights and readings.

8) revise, revise, unpeel, relate, reference, check rewrite edit, edit, edit. Perhaps the hardest thing that we as writers need to learn is not to come to closure too early. After all, writing a book and an exegesis is a hard task: once the first rough draft is there it's easy to breathe a sigh of relief and say 'that's it'. However, very few works are ready for even the ideal reader when they are first drafted.

9) meet supervisors' quasi-examiner advice/demands/expectations. I think that this is perhaps the most difficult and sensitive stage of the candidature. I guess that it occurs towards the second half of the second year, and there has already been a long interpersonal relationship between the supervisor and candidate. In some cases, this might almost be seen by the unwary on each side as a friendship. Transitioning into a quasi-examiner means making this change clear to both parties and agreeing to its importance without losing trust.

10) Submission, waiting, result, exultation, glory! 


\section{The Supervisor's Trajectory}

1-7. 'Hands-on' supportive supervision/interaction

8. Acting as a critical friend:

9. Quasi examiner

10. Submission, waiting, result, exultation, glory!

Changing a traditional knowledge-culture within the academy means confronting academic cultural ideologies that are the unspoken 'givens' that tend to 'glue' the university research group together. We are coming from that culture, so we are formed and informed by it... and perhaps 'blinded' to its social constructions of 'the natural'. However, the ways in which we seek meaning through writing are also the ways in which we can identify the fragility of meaning that comes from the construction of the culture. Nowhere can this be seen more dynamically than in practice led research degrees such as our artefact and exegesis writing degree.

The Indian cultural theorist Gayatari Spivak says of this:

'...leaders read the world in terms of rationality and averages, as if it were a textbook. The world actually writes itself with the many-leveled, unfixable intricacy and openness of a work of literature (Spivak,1988:95)

\section{Some issues of sustainability in relation to creative and practice-led research in the academy}

Sustainability is most often thought of in regard to matters of not exploiting our planet. However, it is increasingly also being applied to matters of culture, social justice, and knowledge. It is my contention that our hybrid PhD structure enables the kind of holistic multi-layered, lateral thinking that encourages sustainability in the sense that:

- $\quad$ it is not defined by traditional templates of learning or views of what knowledge consists of

- $\quad$ it enables disputation and critical thinking by bringing together the Cartesian binary

- $\quad$ it recognises practice as being a leader of research rather than a servant to explicate theories

In this way, new knowledge models are created that are inclusive of difference rather than acting as gatekeepers protecting existing Western dominated methodologies and definitions of knowledge itself.

Sustaining an institution so that it develops rather than remains static is a significant issue for universities which are entering a business phase that seems to be at odds with an academic endeavour. (Dawe et al 2005)

'...creativity is not by any means restricted to the arts, rather it is the intellectual process of conceiving new ideas regardless of the field of endeavour...the inability to be open to trying new approaches and rethinking traditional methodology or the restrictions imposed by overly rigid systems and organisational structures present real barriers to creativity. Without a supportive organisational environment where an element of risk taking is a given there can be little creativity and creative people will not flourish.' (Oakley 2004:3)

Such a sustainability issue is particularly apposite for developing countries.

Anthony Costello, Professor of international child health, and Alimuddin Zumla, Professor of infectious diseases and international health address this by asking:

'What should be the principles behind investment in research in developing countries? Does current practice overemphasise the results of research and ignore issues like ownership, sustainability, and development of national research capacity? (2000:827)

They respond with a scathing indictment of 'foreign research priorities', by averring that: 'We believe that the research model supported by many funding agencies remains semicolonial in nature.' (2000:827)

This report (PP827-8) states that:

'Education for sustainable development is an emerging imperative. It represents a major shift in the way students are taught and learn within the higher education sector. It requires a broader and more flexible approach to the development and teaching of academic disciplines. Much of this change is in line with what graduates will need in an increasingly complex work environment.” (Pp832)

The Academy is by its very nature traditionalist and hence conservative and is based firmly in a Western Enlightenment model. Envisaging the $\mathrm{PhD}$ as a place of contestation in structure as well as substance enables the academic world to do more than validate a pro-forma or templated $\mathrm{PhD}$ model. Rather it opens up for consideration a multi-layered discourse that draws together practicum and the academe into an artist-scholar nexus/praxis. This is rather more than a struggle between the validated and the new: it also provides an opportunity to attempt to describe the new. A traditional PhD is no less an 'authorial announcement' (Kroll 2004.p.4) than an exegesis. Therein too, 
'... writers reveal their personalities as well as their methodologies', even if rather more indirectly and more decently clothed in tradition. However, taking Roland Barthes's (1977) axiom that the author as god is dead and the reader empowered as the co-writer, we understand that it's as applicable to any mode of thetic discourse. It could be asserted that it's most applicable to the traditional mode.

\section{The Knowledge Debate}

Although there appears to be acceptance of doctoral writing in many forms (Richardson 1990), the debate between traditional academic practice and the form of the exegesis is far from over. For example, Barbara Milich and Ann Schilo (2004) suggest that basing both the exegesis and the 'artefact' on a research question enables the relationship between the two elements to result in academic writing that is complementary to the creative component. This, they argue, enables the candidate to display a profound knowledge of the research area and makes clear new contributions, understandings and insights into it. This seems to be an incredibly stilted and excessively definitive model that subsumes the creative component into academic research model verification practices. What they describe as the uneasy relationship between the creative component and the academic might better be seen as the energising moment of writing an openly multi-layered text. How the $\mathrm{PhD}$ candidate achieves this is a necessary part of the substance of the work that becomes clear through the structure of the exegesis as a parallel work.

Clearly, the debate between 'academic writing' and 'the other' is far from over and for many people still quite unresolved. For example, Robert Nelson (2004) describes the traditional thetic/exegesis as rather more of a straightjacket. In doing so, he enables a re-definition for the writing $\mathrm{PhD}$ as 'a cultural contribution of substantial significance' rather than the traditional 'original contribution to knowledge'. At his own University (Monash University, Victoria, Australia) he describes this as being seen as 'a very liberating declaration...received with relief and embraced warmly in amendments to the doctoral regulation' (Nelson 2004.p3) The exegesis is moved from epistemological research terms as its defining characteristic into a 'conceptual background' to the artefact. 'It has to come to life again in order to appear as a significant cultural contribution and hence the writing cannot disappoint the high charter of the creative work. The creative material is in constant rebirthing through the text that sits beside it'. (Nelson 2004.p.3)

To enable this there has to be a recognition that methodology varies from the traditional knowledge model based on scientific methods. Such research is about setting a question and finding data to legitimise or refute it. Barbara Bolt (2004) says of this 'researchers are expected to conceive an outcome in advance, and identify the significance and innovation of the research proposal. Intentionality sets in place preconceptions about what the work will do.' (Bolt 2004.p.4). She notes that such 'intentionality' is the opposite of the creative project that '... emerges in the working process'. and agrees with Giles Deleuze (2003) that the template must be broken by a 'catastrophe occurring' so that the conceptual rhythms of the creative process can occur.

\section{The Exegesis and the Literature Review}

In our Writing Discipline, candidates seem most challenged by the production of the exegesis. Within this, the most challenging aspect is the literature review. The exegesis model enables the weaving throughout of relevant debates and references. It may well be advisable for examination purposes, however, also to have a section that establishes how this work sits within the academic debate and contributes new aspects to it. In discussing a traditional model, Kate Crowley says that '... the literature review plays several roles: structural for its positioning of the thesis, contextual for its scene setting, inspirational for helping develop argument, and operational for defining scope, limitations and originality.' (Crowley 2007:209) This provides useful advice to us in the artefact/exegesis model.

In its structural role, the literature review section/weaving of the exegesis may:

- draw together the artefact and exegesis so that they 'talk to' one another by highlighting the challenges faced and overcome in the production of the exegesis

- contribute a multi-level series of references and concomitant insights from the artifact, other productions in the same genre, other producers'/writers' insights into the process of production and relevant academic and intellectual theories and debates.

- $\quad$ set boundaries to show what is included in the exegesis and what is not within the scope of this work

In its contextual role, the literature review section/weaving of the exegesis may:

- $\quad$ situate the work done in the artefact within an academic debate

- $\quad$ utilize the working journal to follow threads to establish areas of academic reading

- enrich one's own production insights by relevant journal articles including academic and intellectual commentaries, research, methodologies etc. 
In its inspirational role, the literature review section/weaving of the exegesis may:

- indicate the ways in which the production of the artefact has illuminated and been illuminated by current academic debates

- $\quad$ provide insights that are enriching and enlivening for the current intellectual territory

- develop new approaches that enable others to go forward

In its operational role, the literature review section/weaving of the exegesis may:

- $\quad$ act as a place in which the candidate's ideas to be expressed in academic terms that complement the production of the artefact

- $\quad$ introduce cultural and critical theories that develop further academic insights into ideas and attitudes canvassed in or arising from the artifact

- $\quad$ ensure that the examiners have a clear view of the place that the artifact and exegesis are surveying

The pedagogical role and its delicate association with the research role is nowhere more clear than in the structuring of the literature review in the exegesis explicating its relationship to the artefact. The candidate will eventually contribute in a new and significant way to this knowledge. (Thomasson \& van Oudhe 2004)

Candidates in the early stages of the artefact/exegesis $\mathrm{PhD}$ in our writing model often need particular support to begin their 'academic' reading. In the early stages, there is a stage of flux that involves candidates in producing their artefact, working on their writer's journal and reading widely in genre, practice and theory: a big ask. Crowley states of the candidates' relationship with their supervisors in this phase that: 'It is critical that they have confidence in their supervisors and that their supervisors can anticipate the terrain ahead, and so provide meaningful guidance, explicit advice and access to expert knowledge and experience.' (2007:209)

Certainly, in my experience this early stage of the teacher/learner relationship sees the candidate rely upon the supervisor in ways that change as the candidature proceeds. As the candidate becomes more assured and expert, the relationship is more dynamic and interactive and the candidate steps up as the supervisor withdraws. In this process both are acknowledging the expertise of the candidate in their own PLR project.

The research, as well as observations from seasoned supervisors, shows that it is essential that-especially in the early stages but also as submission and examination draws nigh- candidates be helped by a 'hands-on' supervisor. Sinclair's research shows the importance of 'hands on' supervision for the candidate, but I consider it to be valuable for both the candidates and the supervisors. In a successful alliance with candidates, the $\mathrm{PhD}$ supervisor, like any teacher, has to establish the scaffolding for a relationship with candidates that is mutual, deep, intimate, yet detached. The working alliance is quite interactive: there is no sense of Freud's famous (or infamous) 'tabula rasa' of classical analysis in which the supervisor holds back entirely. Rather, the working alliance is co-operative and leads to mutual helpful disclosures, hints, direction-giving, building on academic experiences and insights and even personal and social interactions. Sinclair calls this 'hands-on' and compares it very favourably with its opposite:

'Some supervisors take a 'hands off' approach to supervision that leaves candidates largely to their own devices. Except in a minority of cases where beginning candidates are already self-confident, independent, knowledgeable, skilled, organised and socially adroit, 'hands off' approaches tend to be associated with slow and non-completion.' (Sinclair 2004:vi)

\section{The Supervisor as a 'critical friend'}

Teaching and learning in the PhD program is a lively example of the supervisor as a 'critical friend'. In this role, supervisors are both supportive and critical. They encourage candidates to think, read, research, discover and enact beyond what is readily achievable. Whilst each research activity is and must be unique, there are commonalities in enacting the teaching and learning process described by Sinclair as 'hands on'.

Ed Carson suggests that this should occur at what he calls 'critical points of the candidacy'. (2007:58). He also avers that frequent planned meetings and regular feedback are essential elements of $\mathrm{PhD}$ pedagogy, and these should be based on early agreements:

'early in the candidacy, it is essential to specify (negotiate) expectations about supervisory styles, including the frequency of meetings and reviews', and 'more generally, in addition to scholarly and administrative support, the supervisor needs to provide some pastoral care and motivational support'. (2007:59)

The supervisor is engaged in a subtle interaction between teaching and learning about and towards independent research capacities for the candidate. There should be no sense of a paradox existing between supervising for independence and supervision as a pedagogical practice. Teaching is at its best when there is a rich interactive 
relationship allowing a co-construction of learning. The implications of the term 'critical friend' are sophisticated and quite appropriate to consider and interrogate as a descriptor of PhD pedagogy. It explicates what Sinclair calls a 'hands on' supervisor, and also covers those aspects of personal interaction involved in such a close and fairly long-term relationship. The pedagogical critical friend is, for example:

1) positive in their critical evaluations.

2) acting to enable and enrich the work rather than promote or display their own status and intellectual abilities.

3) discussing and reading the work with insightful respect while at the same time being prepared to identify what they consider to be its strengths and how they perceive the weaknesses.

4) one who spends considerable time on multiple readings while taking notes and making marks on the manuscript.

5) able to bring their knowledge and understanding of the research processes to the area in which candidates are working. They should apply it to show how candidates might alter their work so as to address the faults or weaknesses they have found in it.

6) an editor and examiner as well as mentor and teacher. The critical friendship should not be confined to details of content, spelling or grammar, although they should address these. It should also encompass the imaginative, creative, individual and personal aspects of the conceptual side of the candidates' thinking and writing.

\section{PhD supervision and/as pedagogy}

To enable us to feel confident in our $\mathrm{PhD}$ teaching and learning interactions, teacher/learning training in $\mathrm{PhD}$ pedagogy is invaluable. 'Supervising research candidates is a process that renews and revitalises the supervisors. They learn from their candidates' findings, are challenged by their new ideas and approaches, and vicariously celebrate their achievements.' (Denholm and Evans. 2007:269)

There is much debate about $\mathrm{PhD}$ supervision being seen/practised as pedagogy, and increasing academic publication and University practices and regulations about it. (Grant and Pearson. 2007:16). Universities increasingly have some formal means of supervisor-training, whereas until quite recently this was fleeting or rare (Johnson et al 2000). All of the supervisors interviewed by Mark Sinclair for his in-depth quite recent Australian study '...learned their supervisory knowledge and skills informally, on-the-job...' (Sinclair 2004:23). This is also true, of course of the pedagogical training for the majority of University lectures and tutors who were traditionally rarely if ever required to have any teacher training. This trend is being challenged in Australia in the $21^{\text {st }}$ century in response to new Federal funding regimes.

Rather than defining and announcing itself as a teaching and learning event, Sinclair says that 'The $\mathrm{PhD}$ candidature appears to be a rite of passage into distinct research cultures that manifests in discipline-specific completions and times to submission.' (2004:iv) Yet the candidacy occurs in real-life, real-time and has very particular goals and outcomes: it changes candidates' lives. The importance of empathy, warmth, congruence, complex verbal skills, approval, supportiveness, optimism and respect is significant and central to any learning and teaching engagement: it's not less in supervising a PhD candidate. Indeed, it may be more acute as the interaction becomes an intense one on one of teacher, mentor, guide, colleague, critical friend and...particularly in the final stages...quasi-examiner who must ultimately recognise the superior knowledge of the candidate within the chosen thetic area.

Barbara Grant and Margot Pearson state that: 'as reliance on supervision as a set of informal practices gives way to more formalised articulations of roles and responsibilities, there is more institutional attention to the pedagogy of supervision and the nuances of this complex process' (2007:13) This professional development addresses questions such as effectiveness, reporting, obligations, university protocols, teaching skills, communication and negotiation skills, responsibilities of supervisors and candidates, examination processes, advice to examiners and candidates from relevant faculties and collegiality and mentoring of fellow staff.

Developing Practice Led Research in the writing PhD is a pedagogical challenge (Fletcher and Mann 2005),. (Arnold 2007). In addressing the advantage given to the Natural Sciences model of PhD candidature, thesis and supervision, Sinclair notes that a '...breadth and depth of prior research experience is less likely among academics in the Social Sciences and the Humanities and Arts before they commence supervisory duties.' (2004:24) In the case of supervising PLR, this needs some attention. Many supervisors are themselves practitioners. For example, in setting up and supervising the PhD by artefact and exegesis from the Writing Discipline, I had over 45 commercially published books in a large number of 'non-academic' genres.

Sinclair states that further comparisons between the Natural Sciences model and the Social Sciences, Humanities and Arts display further disadvantages institutionalised against the latter. For the latter, these disadvantages involve: 
- ambitious, individual and even creative theses

- $\quad$ no cohort to support in-house

- less intense supervisory interactions in-house

- less pressure to compete because of industry stakeholder investment

- fewer scholarships

- no postdoctoral expectations

- $\quad$ more part-timers

\section{The Cartesian binary vs. Practice Led Research}

There is no single model of Practice Led Research: rather the term is an umbrella term indicating that the practice leads the research rather than being announced as merely the subject of it. PLR in the writing model varies considerably from the model of research groups common in the natural sciences. (Sinclair 2004:16) The PhD in the Writing Discipline accords closely to the Humanities and Arts supervisions where, according to Sinclair , '...candidates in this model are typically not involved with research groups or teams on a regular basis and the presence of postdoctoral staff is rare'. He compares this unfavourably with the Natural Sciences where 'peer support of fellow candidates and the higher frequency of interactions with official and unofficial supervisors' promote a culture that enriches official supervision.' (Sinclair 2004:17) This describes the traditional PhD model better than any PLR model. The practitioner has her or his own ways of working. They are usually very creative people who need to work in their own ways on their practice, and this is often quite alone. Where group contact is valuable is in relationship to the academic side of their work. One of the ways we've facilitated this is to have an online space for them to converse, another is a regular newsletter and yet another is a yearly colloquium at which they present.

As I see it, the Practice Led Research model here in the Writing Discipline at Swinburne University of Technology is suited to the Arts and Social Sciences for many reasons. For me, the most important is that it addresses the limits the Cartesian binary places upon research models and practices in the Arts and Social Sciences. The Cartesian binary that underpinned the Enlightenment has resulted in some wonderful advances in knowledge that have established the quantitative model espoused by the natural sciences. At the same time, it set the scene for the qualitative vs. quantitative debate that has overshadowed non-traditional modes of enquiry. Rather than 'cogito ergo sum' that sets reason above all other forms of human enquiry and knowledge, the $21^{\text {st }}$ century, following the postmodernist dispersal of paradigmatic thought, has begun to accept alternative ways of knowing, These draw together multiple ways of thought, enquiry, research, theory and practice.

In her discussions of the need to readdress and essentially redress the Cartesian binary, Mary Midgely contends that: '...all reasoning is powered by feeling and all serious feeling has some reasoning as its skeleton. Thought and feeling are not opponents, any more than shape and size'. (2004:9). Midgely sees traditional research based on the natural sciences as one of the myths that we live by that produce '...patterns of thought that are really useful in one age [that] can make serious trouble in the next one.' (2004:4) In this sense, traditional research constructs proclaim themselves as logical and reasonable within a given framework and then establish, de facto, that framework as the 'norm' by which all other research is judged. The PLR learning and teaching arc is quite different from these 'norms'. Thus it presents possibilities for different ways of knowing, for different teaching and learning interactions and for different and more diverse demographics to enter the PhD programs.

\section{Lifelong Learning}

Traditionally, the PhD had a narrow focus for an academic career. Today, candidates undertake PhDs for a variety of reasons, at different stages in their lives and from differing credentialled and uncredentialled knowledge-bases. This is particularly evident in Practice Led Research degrees such as the Swinburne Writing Discipline PhD by artefact and exegesis. At the same time as recognising this, it is also evident that a significant aspect of learning is reaching an understanding of where it is taking you.

Learning for life and lifelong learning are considerations that are becoming more and more emphasised in higher education. This is a considerable aspect of the $\mathrm{PhD}$ pedagogical journey for both candidate and supervisor. Part of the pedagogical role of the supervisor is to advise and aid the $\mathrm{PhD}$ candidate on this aspect of their learning journey. Andrew Cheetam et al state that not only is there life after the doctorate, but that it is important that:

'...this journey is well planned, is productive and properly prepares the candidate for their career... supervisors have an important role in broadening a candidate's horizon in terms of the range of possibilities and strategies to achieve their aspirations.' (2007:252/3) 
As candidates' work matures, so their goals may change. For me, it is an important aspect of the PhD pedagogy to recognise and support this. Cheetham et al suggest that a projection 5 years beyond the doctorate is valuable. (2007:255) One way to enhance this is to isolate the skills that candidates bring to the candidature and that they develop during the candidature. Each candidate will bring different skills and develop different abilities. In the Practice Led Research $\mathrm{PhD}$ in writing, they will most probably include a generic set such as:

- the ability to set goals beyond one's current competencies

- $\quad$ capacities to work strategically and fruitfully to obtain such goals

- $\quad$ abilities to map a timeline of deliverables and to meet it

- creative insights into the production of an artefact

- $\quad$ abilities to develop and produce an artefact at a high level of production values relevant to the genre

- $\quad$ energy and enthusiasm to work creatively

- $\quad$ willingness to address and connect academic and intellectual ideas about theory and practice

- $\quad$ a readiness to think beyond the artefact production to intellectual and academic challenges and matrices

- $\quad$ outstanding communication skills

- $\quad$ the ability to network

- the ability to set achievable and reasonable goals

- $\quad$ understanding of the establishment and use of boundaries

- $\quad$ some work experience

- understanding how to identify and use relevant resources, especially career resources, inside and outside the university

- $\quad$ understanding of cyber opportunities

- $\quad$ insights into graduate career opportunities and their relationship to the knowledge economy

These skills need to be isolated, recognised and taken into the candidates' curriculum vitae. The supervisor is acting pedagogically in enabling this activity. Peter Tatham and Carey Denholm call this 'marketing the candidate' (2007: 267) They say this time of transition is both fragile and potentially fertile. 'The significant issues for the candidate are how to balance the acquired skills, vulnerability and the uncertainty in locating relevant employment, along with a realistic appraisal of their personal potential.' (2007:267). They suggest that supervisors can help in this 'potentially life-changing' (2007:268) process by such interactions as:

- Knowing the relevant labour market

- Understanding employer expectations

- $\quad$ Enabling the identification and packaging of relevant employable skills

- Identifying with the candidates and selling to them the abilities developed by candidates and brought to the candidature

- Differentiating opportunities for consultancy from those offered in employment

- $\quad$ Supporting the candidates self-confidence

- Actively planning the future with candidates

It is apparent that this interaction between candidate and supervisor is not one of traditional dedicated and disinterested research development: it is a pedagogical intervention. (Rowarth \$ Fraser 2007)

\section{Conclusion}

Changing a traditional knowledge-culture within the academy means confronting academic cultural ideologies that are the unspoken 'givens' that tend to 'glue' the university research group together. We are coming from that culture, so we are formed and informed by it... and perhaps 'blinded' to its social constructions of 'the natural'. However, the ways in which we seek meaning through writing are also the ways in which we can identify the fragility of meaning that comes from the construction of the culture. Nowhere can this be seen more dynamically than in practice led research degrees such as our artefact and exegesis writing degree.

The Indian cultural theorist Gayatari Spivak says of this: '...leaders read the world in terms of rationality and averages, as if it were a textbook. The world actually writes itself with the many-leveled, unfixable intricacy and 
openness of a work of literature' (Spivak,1988)

What, then, in Practice Led Research is the relationship between 'aesthetic quality', 'research' and 'professional qualities/viability' in relation to outcomes/outputs? This question brings to the fore the interesting and challenging debate about what is seen/understood to be knowledge within the academy. (Barron; Bourke \& Neilson 1996) The $\mathrm{PhD}$ by artefact and exegesis acknowledges that practice leads the research while at the same time seeing that the practice is not stand-alone within the academy.(Candy et al. 2007). The exegesis doesn't validate the practice as knowledge, rather it explicates how the practice is knowledge for both the academy and for the practitioner. This is an important point: the practice is enriched through reflection upon itself in both practitioner terms and further in bringing that practice into the academy to develop understanding of the extension of knowledge past/through the Cartesian binary.

It is true that a $\mathrm{PhD}$ must consist of:

1) an original piece of research. a new and substantial contribution to knowledge

2) insights that lead to the candidate being expert in that aspect of their field

'An acceptable doctoral thesis makes substantive, original contribution to knowledge. It must be on a topic of significance to the discipline, grounded in appropriate methodology, sufficiently weighty to prompt thought and discussion, and produce something new.' (Rowarth \& Fraser. 2007:224)

It is also true that the $\mathrm{PhD}$ candidate and supervisor are always on a singular journey whatever the constraints and demands of the academic area. Like many journeys, the setting-out is full of enthusiasm.

'Most candidates, having selected their area of research in broad terms, arrive with high levels of motivation, enthusiasm and energy. They are eager to start on the path towards achieving their masters or doctoral degree but have only a vague notion of how to proceed. In the beginning stage the influence of the supervisor is critical.' (Moltschaniwskyj and Moltschaniwskyj 2007:28.)

Like many journeys, it is also necessary to plan and understand the terrain.

Ed Carson advises that:

'...by explicitly considering the range of elements involved in undertaking the complex enterprise that is the doctorate, supervisors can help support the candidate to complete in a way that suits their needs and the parameters of the research, but also to complete in an effective and less stressful way than might otherwise be the case.' (2007:61)

This paper has explored how the artefact and exegesis $\mathrm{PhD}$ offers an opportunity to bring creative activity together with academic debate and intellectual rigour. In utilising a methodology within this paper of the 'subjective academic narrative', I have explicated that every piece of knowledge is a part of the story of the subjective self within the domain of the academic: it is what Gregory Ulmer would call a 'mystory' Thus it is both mysterious and explicatory in its story-telling. Such narratives are becoming more common within all forms of academic discourse, but are particularly suited to the social sciences and the arts.

\section{References}

Arnold, J. (2005). The PhD in Creative Writing Accompanied by an Exegesis. Journal of University Teaching and Learning Practice. 1(1), pp36-50. [Online] Available: http://jutlp.uow.edu.au/ (March 12, 2009).

Arnold, J. (2007). 'Practice Led Research: A dynamic way to knowledge.' The Rock View Press. Melbourne. Australia.

Arnold, J. (2010). The liminal and apophatic voice of the writer in/as autobiography: a subjective academic narrative. Text. 1(1). April 2010.

Barron, D \& Zeegers, M. 'O' for Osmosis, 'P' for Pedagogy: Fixing the postgraduate wheel of fortune. [Online] Available: http://www.aare.edu.au/02pap/bar02605.htm. (August 22, 2009).

Barthes, R. (1977). Image-Music-Text. Essays selected and translated by Stephen Heath. London. Fontana/Collins.

Bolt, B. (2004). The exegesis and the shock of the new. In TEXT Special Issue, 3. [Online] Available: http://www.griffith.edu.au/school/art/text/speciss/issue3/bourke.htm (December 12, 2009).

Bourke, N., \& Neilson, P. (1996). The problem of the exegesis in creative writing higher degrees. TEXT Special Issue. 3. [Online] Available: http://www.griffith.edu.au/school/art/text/speciss/issue3/bourke.htm (December 12, 2009).

Brien, D. (1996). The problem of where to start: a foundation question for creative writing higher degree candidates 
and supervisors. TEXT Special $\quad$ Issue. $3 . \quad$ [Online] Available: http://www.griffith.edu.au/school/art/text/speciss/issue3/brien.htm (August 22, 2009).

Candy, L, Amitani, S., \& Bilda, Z. (2007). Practice-led strategies for interactive art research. In: CoDesign. Dec. 2006, 1(4), P209-223.

Carson, E (2007). Helping candidates manage their candidacy. In Denholm, C and Evans, T. (eds) 2007. Supervising doctorates downunder. Keys to effective supervision in Australia and New Zealand. Pp. 54-61. Victoria. Australia. A.C.E.R.

Cheetam, A. Blood, R. Daly, A., \& Maher, B. Assisting candidates as they move into postdoctoral life. In Denholm, C and Evans, T. (eds) 2007. Supervising doctorates downunder. Keys to effective supervision in Australia and New Zealand. Pp. 251-260. Victoria. Australia. A.C.E.R

Costello, A., \& Zumla, A. (2000). Moving to research partnerships in developing countries. In: British Medical Journal. 2000; 321. 30 September. Pp. 827-829

Crowley, K. (2007). The literature review: Not sinking, writing. In Denholm, C and Evans, T. (eds) 2007. Supervising doctorates downunder. Keys to effective supervision in Australia and New Zealand. Pp. 208-214. Victoria. Australia. A.C.E.R.

Dawe, G. Jucker, R., \& Martin, S. (2005). Sustainable Development in Higher Education: Current practice and future developments. A report to the Higher Education Academy. November 1005. Innovation Way, York Science Park, Heslington, York.

Deleuze, G. (2003). Francis Bacon and the Logic of Sensation. London. Continuum.

Denholm, C \& Evans, T. (2007). Supervising doctorates downunder. Keys to effective supervision in Australia and New Zealand. Victoria. Australia.A.C.E.R.

Department of State \& Regional Development. (2008). NSW Creative Industry Economic Fundamentals.

Fletcher, J., \& Mann, A. (2004). Illuminating the exegesis. In Text Special Issu, 3. [Online] Available: http://www.textjournal.com.au/speciss/issue3/content.htm (December 10, 2009)

Gallop, J. (2002). Anecdotal Theory. U.S.A. Duke University Press

Grant, B. (2005). Fighting for space in supervision: fantasies, fairytales, fictions and fallacies. In the International Journal of Qualitative Studies in Education, 18(3). May-June 2005. pp337-354.

Grant, B., \& Pearson, M. (2007). Approaches to doctoral supervision in Australia and Aotearoa New Zealand. In Denholm, C and Evans, T. (eds) (2007). Supervising doctorates downunder. Keys to effective supervision in Australia and New Zealand. Pp. 11-18. Victoria. Australia. A.C.E.R.

Green, L. (2006). creative writing as practice-led research In Australian Journal of Communication. 01/09/2006. 33(2/3). P175-188.

Harper, G. (2008). Creative writing: words as practice-led research. In Journal of Visual Art Practice. 2008, 7(2). P161-171. http://dx.doi.org/10.1386/jvap.7.2.161_1

Holt, N. (2003). Representation, Legitimation, and Autoethnography: An Autoethnographic Writing Story. In: International Journal of Qualitative Methods. Pp 18-28.

James, R., \& Baldwin, G. (1999). Eleven Practices of effective postgraduate supervisors. Australia. Melbourne: The Centre for the Study of Higher Education and The School of Graduate Studies, University of Melbourne.

Johnson, L. Lee, A., \& Green, B. (2000). The PhD and the autonomous self: gender, rationality and postgraduate pedagogy. In Studies in Higher Education, 25(2). pp135-147. http://dx.doi.org/10.1080/713696141

Kroll, J. (2004). The exegesis and the gentle reader/writer. In Text Special Issue. [Online] Available: Http://www.griffith.edu.au/school/art/text/ (December 10, 2009)

Maarit, M. (2007). Knowing through making: The role of the artefact in practice-led research. In: Knowledge, Technology \& Policy. Fall 2007, 20(3). P157-163.

Midgely, M. (2004). The myths we live by. Oxon and New York. Routledge

Milich, B., \& Schilo, A. (2004). "Exit Jesus': Relating the exegesis and creative/production componenets of a research thesis. In Text Special Issue. [Online] Available: Http://www.griffith.edu.au/school/art/text/ (December 10, 2009)

Moltschaniwskyj, N., \& Moltschaniwskyj, G. (2007). Setting the scene: Initiating the supervision relationship. In 
Denholm, C and Evans, T. (eds) (2007). Supervising doctorates downunder. Keys to effective supervision in Australia and New Zealand. Pp. 224-232. Victoria. Australia. A.C.E.R.

Nelson, R. (2004). Doctoralness in the balance: The agonies of scholarly writing in studio research degrees. Text Special Issue. [Online] Available: Http://www.griffith.edu.au/school/art/text/ (December 10, 2009)

Oakley, K. (2004). Not so cool Britannia: The role of the creative industries in economic development. In International Journal of Cultural Studies. 2004, 7, 67. http://dx.doi.org/10.1177/1367877904040606

Rowarth, J., \& Fraser, G. (2007). Determining doctoral quality. In Denholm, C and Evans, T. (eds) 2007. Supervising doctorates downunder. Keys to effective supervision in Australia and New Zealand. Pp. 224-232. Victoria. Australia. A.C.E.R.

Sinclair, M. (2004). The pedagogy of 'good' PhD supervision: a national cross-disciplinary investigation of PhD supervision. Australia. Dept. of Education, Science and Training.

Singer, P. (2009). We Must Nurture The Humanities. Melbourne. Australia. The Age newspaper. 27/07/09. Pp15.

Spivak, G. (1988). In Other Worlds. Essays in Cultural Politics. London. Routledge.

Tatham, P., \& Denholm, C. (2007). Developing career management skills in candidates. In Denholm, C and Evans, T. (eds) 2007. Supervising doctorates downunder. Keys to effective supervision in Australia and New Zealand. Pp. 261-268. Victoria. Australia. A.C.E.R.

Thomassen, A., \& van Oudheusden, M. (2004). Knowledge creation and exchange within research: the exegesis approach. Working papers in art and design, 3. http://herts.ac.uk/artdes1/research/papers/wpades/vol3/atfull.html (August 22, 2007).

Ulmer, G (1985). Applied Grammatology: Post(e) Pedagogy from Jacques Derrida to Joseph Beuys. Baltimore. John Hopkins University Press.

Wall, S. (2006). An Autoethnography on Learning About Autoethnography. In: International Journal of Qualitative Mrethods. PP.146-160.

\section{Author}

Dr Josie Arnold is the inaugural Professor of Writing at Swinburne University of Technology. She established the Master of Arts (Writing) online course and the $\mathrm{PhD}$ in writing by artefact and exegesis. She has won University and national teaching awards and published over 45 books in a wide variety of genres. 


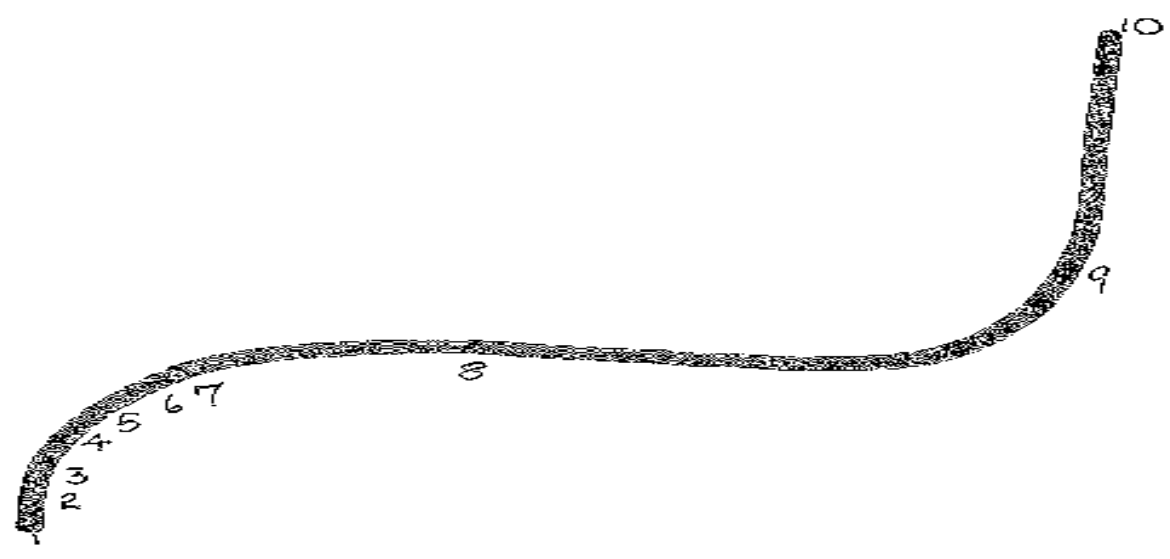

Figure 1. My simple visual model of the supervisory/candidature trajectory 